\title{
Updating The Accuracy of Administrative Claims for Identifying Left Ventricular Ejection Fraction Among Patients with Heart Failure
}

\author{
Alexander T Sandhu, MD, MS, ${ }^{\mathrm{a}, \mathrm{b}}$ Jimmy Zheng, BS, ${ }^{\mathrm{c}}$ Paul A Heidenreich, MD, MS ${ }^{\mathrm{a}, \mathrm{b}}$
}

\author{
Affiliations: \\ ${ }^{a}$ Division of Cardiovascular Medicine, Department of Medicine, Stanford University, Stanford, \\ CA \\ b Department of Medicine, Palo Alto VA Veteran's Affairs Hospitals, Palo Alto, CA \\ ${ }^{\mathrm{c}}$ Stanford University School of Medicine, Stanford, CA
}

Funding: ATS is supported by a grant from the NHLBI (1K23HL151672-01). 


\begin{abstract}

\section{Introduction:}

Left ventricular ejection fraction $(\mathrm{EF})$ is an important factor for treatment decisions for heart failure. The EF is unavailable in administrative claims. We sought to evaluate the predictive accuracy of claims diagnoses for classifying heart failure with reduced ejection fraction (HFrEF) versus heart failure with preserved ejection fraction $(\mathrm{HFpEF})$ with International Classification of Disease-Tenth Revision codes.
\end{abstract}

\title{
Methods:
}

We identified HF diagnoses for VA patients between 2017-2019 and extracted the EF from clinical notes and imaging reports using a VA natural language processing algorithm. We classified sets of codes as HFrEF-related, HFpEF-related, or non-specific based on the closest EF within 180 days. We selected a random heart failure diagnosis for each patient and tested the predictive accuracy of various algorithms for identifying HFrEF using the last 1 year of heart failure diagnoses. We performed sensitivity analyses on the EF thresholds, the cohort, and the diagnoses used.

\section{Results:}

Between 2017-2019, we identified 358,172 patients and 1,671,084 diagnoses with an EF recording within 180 days. After dividing diagnoses into HFrEF-related, HFpEF-related, or nonspecific, we found using the proportion of specific diagnoses classified as HFrEF-related had an AUC of 0.76 for predicting $\mathrm{EF} \leq 40 \%$ and 0.80 for predicting $\mathrm{EF}<50 \%$. However, $23.3 \%$ of patients could not be classified due to only having non-specific codes. Predictive accuracy increased among patients with $\geq 4 \mathrm{HF}$ diagnoses over the preceding year.

\section{Discussion:}

In a VA cohort, administrative claims with ICD-10 codes had moderate accuracy for identifying reduced ejection fraction. This level of specificity is likely inadequate for performance measures. Administrative claims need to better align terminology with relevant clinical definitions. 
medRxiv preprint doi: https://doi.org/10.1101/2021.09.15.21263651; this version posted September 17, 2021. The copyright holder for this

Left ventricular ejection fraction (EF) is a critical factor in determining guideline-directed therapy for patients with heart failure (HF). However, EF is unavailable in administrative claims, limiting use of these data for quality measures or clinical research. Previous analyses of inpatient HF using International Classification of Disease-Ninth Revision (ICD-9) codes demonstrated low sensitivity for identifying HF patients with reduced $(\mathrm{rEF})$ or preserved ejection fraction $(\mathrm{pEF}) .{ }^{1-3}$ We used the Veteran's Affairs (VA) natural language processing algorithm for EF to evaluate the predictive accuracy of ICD-10 HF codes.

\section{METHODS}

We identified HF diagnoses for VA patients between 2017-2019 from VA, non-VA fee care, and Medicare administrative claims. We leveraged a validated natural language processing algorithm with $>95 \%$ precision to extract EF from clinical notes and imaging reports. ${ }^{4}$ We excluded EF with ranges exceeding $10 \%$ as potential errors.

For each diagnosis, we identified the closest EF within 180 days. We then determined the proportion with $\mathrm{EF} \leq 40 \%, 40-50 \%$, or $\geq 50 \%$ across codes (Table 1). We classified codes as HFrEF-related if over half had $\mathrm{EF} \leq 40 \%$ and HFpEF-related if over half had $\mathrm{EF} \geq 50 \%$. We termed codes that met neither criterion or had total count $<1,000$ as non-specific.

To test EF classification using multiple diagnoses, we identified a random diagnosis between 2018-2019 for each patient and all HF diagnoses in the prior year. We evaluated two patientlevel predictors: (1) the proportion of specific HF diagnoses classified as HFrEF-related and (2) the proportion of all HF diagnoses classified as HFrEF-related. We then assessed three thresholds for identifying HFrEF: $>0$ (i.e., any HFrEF diagnosis), $\geq 0.5$, and 1 (i.e., all $\mathrm{HFrEF}$ diagnoses). We calculated the area under the curve (AUC), sensitivity, and positive predictive value (PPV) for identifying $\mathrm{EF} \leq 40 \%, \leq 45 \%$, and $<50 \%$.

We performed multiple sensitivity analyses: (1) only clinician evaluation and management or inpatient principal diagnoses, (2) inpatient principal diagnosis alone, (3) EF within 30 days of diagnosis, (4) patients with $\geq 4$ diagnoses, and (5) diagnoses within prior 90 days.

\section{RESULTS}

Between 2017-2019, we identified 11,817,035 HF diagnoses across 993,408 individuals. There were 358,172 patients and 1,671,084 diagnoses with an EF recording within 180 days. This included 398,650 (23.9\%) VA outpatient, 652,716 (39.1\%) VA inpatient, 279,729 (16.7\%) nonVA outpatient, and 339,989 (20.3\%) non-VA inpatient diagnoses. The median absolute time between diagnosis and EF recording was 1 day (IQR: 1-14 days). The median EF was $43 \%$ (IQR: 30-55\%).

Table 1 lists the EF subgroup breakdown $(\mathrm{EF} \leq 40 \%, 40-50 \%, \geq 50 \%)$ for each HF code. Among the 523,718 diagnoses classified as $\mathrm{HFrEF}, 67.6 \%$ had $\mathrm{EF} \leq 40 \%$ compared with $16.6 \%$ with $\mathrm{EF} \geq 50 \%$. Among the 287,916 diagnoses classified as $\mathrm{HFpEF}, 77.6 \%$ had $\mathrm{EF} \geq 50 \%$ compared with $13.5 \%$ with $\mathrm{EF} \leq 40 \%$. There were 859,450 non-specific diagnoses. 
medRxiv preprint doi: https://doi.org/10.1101/2021.09.15.21263651; this version posted September 17, 2021. The copyright holder for this preprint (which was not certified by peer review) is the author/funder, who has granted medRxiv a license to display the preprint in perpetuity. All rights reserved. No reuse allowed without permission.

We identified a random diagnosis for 274,202 patients between 2018-2019 with an average age of 74.0 (SD: 10.5) and only $2.6 \%$ being women. The median number of total HF diagnoses in the prior year was 2 (IQR: 2-4).

Table 1 displays the performance of our predictors. Predictor 1 used the proportion of specific diagnoses classified as HFrEF-related. The AUC for predicting $\mathrm{EF} \leq 40 \%$ was 0.76 , which increased to 0.80 for $\mathrm{EF}<50 \% .23 .3 \%$ of patients had only non-specific HF diagnoses and were not characterized. Using the proportion of all diagnoses classified as HFrEF-related (predictor 2) enabled predictions across the cohort but with decreased AUC of 0.73. Predictor 1 performed better among patients with $\geq 4$ diagnoses in the prior year (AUC 0.79 for $\mathrm{EF} \leq 40 \%$ ). At a threshold of $>0$ (at least $1 \mathrm{HFrEF}$ diagnosis), sensitivity was $94.9 \%$ and PPV was $61.8 \%$. Requiring all diagnoses to be classified as HFrEF increased specificity to $72.1 \%$ but decreased sensitivity to $77.7 \%$.

\section{DISCUSSION}

Across a large VA patient cohort, administrative claims provided moderate accuracy (AUC 0.76) at identifying HFrEF using the proportion of specific HF diagnoses classified as HFrEF-related. However, a quarter of patients could not be analyzed due to only having non-specific diagnoses.

HFrEF classification improved with an EF threshold of $<50 \%$ because clinicians frequently use systolic dysfunction codes for mid-range EF. However, clinical evidence and performance measures focus on $\mathrm{EF} \leq 40 \%$. This limits the utility of administrative codes for identifying performance measure populations as over 1 in 3 patients classified as $\mathrm{HFrEF}$ have an EF $>40 \%$.

Desai and colleagues developed a claims-based EF classification model based on a cohort of 7,001 patients spanning ICD-9/ICD-10. ${ }^{1}$ Their algorithm predicted $\mathrm{EF} \leq 45 \%$ with a sensitivity of $32 \%$ and a PPV of $0.72 .{ }^{4}$ We achieved higher sensitivity by using multiple diagnoses over a 1year period and including the I50.4X codes, which they classified as unspecified HF. Incorporating other patient-level variables may also improve classification. However, an algorithm that incorporates prior treatment or comorbidities may influence its validity for evaluating quality of care.

Current HF diagnosis codes likely remain inadequate for defining populations for quality measures. Research using administrative data should be cognizant of misclassification risk. Administrative coding requires better alignment with clinical definitions to maximize quality improvement and research. Fortunately, ICD-11 designates specific diagnoses for EF subgroups. Until then, studying heart failure with claims data will remain challenging. 
medRxiv preprint doi: https://doi.org/10.1101/2021.09.15.21263651; this version posted September 17, 2021. The copyright holder for this preprint (which was not certified by peer review) is the author/funder, who has granted medRxiv a license to display the preprint in perpetuity. All rights reserved. No reuse allowed without permission.

Table 1. Performance of HF Diagnosis Claims for Classifying Ejection Fraction

\begin{tabular}{|c|c|c|c|c|c|c|c|c|c|}
\hline \multicolumn{10}{|c|}{ Diagnosis-Level Analysis } \\
\hline Diagnosis* & Code & Count & \multicolumn{2}{|c|}{$\mathrm{EF} \leq \mathbf{4 0 \%}$} & \multicolumn{2}{|c|}{ EF $40-50 \%$} & $\mathrm{EF} \geq \mathbf{5 0 \%}$ & \multicolumn{2}{|c|}{ Classification } \\
\hline \multicolumn{2}{|l|}{ All Codes } & $1,671,084$ & \multicolumn{2}{|c|}{$45.8 \%$} & \multicolumn{2}{|l|}{$13.5 \%$} & $40.7 \%$ & \multicolumn{2}{|r|}{-} \\
\hline $\begin{array}{l}\text { Left Ventricular } \\
\text { Failure Unspecified }\end{array}$ & I50.1 & 12,007 & \multicolumn{2}{|c|}{$43.8 \%$} & \multicolumn{2}{|l|}{$16.8 \%$} & $39.5 \%$ & \multicolumn{2}{|c|}{ Non-specific } \\
\hline Systolic HF & $\mathrm{I} 50.2 \mathrm{X}$ & 414,989 & \multicolumn{2}{|c|}{$69.3 \%$} & \multicolumn{2}{|l|}{$15.5 \%$} & $15.2 \%$ & \multicolumn{2}{|c|}{$\mathrm{rEF}$} \\
\hline Diastolic HF & I50.3X & 281,254 & \multicolumn{2}{|c|}{$13.4 \%$} & \multicolumn{2}{|l|}{$8.9 \%$} & $77.7 \%$ & \multicolumn{2}{|c|}{$\mathrm{pEF}$} \\
\hline $\begin{array}{l}\text { Combined Systolic } \\
\text { and Diastolic HF }\end{array}$ & $\mathrm{I} 50.4 \mathrm{X}$ & 100,733 & \multicolumn{2}{|c|}{$59.4 \%$} & \multicolumn{2}{|l|}{$18.0 \%$} & $22.5 \%$ & \multicolumn{2}{|c|}{$\mathrm{rEF}$} \\
\hline Right HF & $\begin{array}{l}\text { I50.810- } \\
\text { I50.813 }\end{array}$ & 6,662 & \multicolumn{2}{|c|}{$18.9 \%$} & \multicolumn{2}{|l|}{$9.3 \%$} & $71.8 \%$ & \multicolumn{2}{|c|}{$\mathrm{pEF}$} \\
\hline Biventricular HF & I50.82 & 4,534 & \multicolumn{2}{|c|}{$70.1 \%$} & \multicolumn{2}{|l|}{$11.4 \%$} & $18.5 \%$ & \multicolumn{2}{|c|}{$\mathrm{rEF}$} \\
\hline End-stage HF & I50.84 & 3,462 & \multicolumn{2}{|c|}{$85.7 \%$} & $4.6 \%$ & & $9.6 \%$ & & $\mathrm{EF}$ \\
\hline Other HF & I50.89-I50.9 & 295,380 & 43. & & $13.2 \%$ & & $43.6 \%$ & Non & specific \\
\hline $\begin{array}{c}\text { Hypertensive Heart } \\
\text { Disease with HF }\end{array}$ & $\begin{array}{c}\text { I1 1.0, I13.0, } \\
\text { I13.2 }\end{array}$ & 551,503 & 43. & & $13.8 \%$ & & $42.9 \%$ & Non & specific \\
\hline & & atient-Lev & Analy & $\mathbf{s}(\mathrm{n}=\mathbf{2 7}$ & $4,202)$ & & & & \\
\hline Prodictor & \% Clascified & FF & $\mathbf{A U C}$ & Thres & hold $>0$ & Threst & hold $\geq 0.5$ & Thre & hold 1 \\
\hline f Fection & o Classincu & $\mathbf{E F}$ & AUC & Sn & PPV & Sn & PPV & Sn & PPV \\
\hline & & $\leq 40 \%$ & 0.76 & $91.2 \%$ & $59.5 \%$ & $90.3 \%$ & $61.1 \%$ & $83.4 \%$ & $63.2 \%$ \\
\hline $\begin{array}{l}\text { (1) Proportion of } \\
\text { Snecific HF Codes }\end{array}$ & $76.7 \%$ & $\leq 45 \%$ & 0.79 & $89.9 \%$ & $71.6 \%$ & $88.7 \%$ & $73.3 \%$ & $81.4 \%$ & $75.3 \%$ \\
\hline & & $<50 \%$ & 0.81 & $88.6 \%$ & $77.1 \%$ & $87.3 \%$ & $81.2 \%$ & $79.9 \%$ & $83.0 \%$ \\
\hline & & $\leq 40 \%$ & 0.73 & $75.1 \%$ & $59.5 \%$ & $59.2 \%$ & $62.7 \%$ & $15.0 \%$ & $59.6 \%$ \\
\hline (2) Proportion of & $100.0 \%$ & $\leq 45 \%$ & 0.75 & $73.4 \%$ & $71.6 \%$ & $57.5 \%$ & $74.8 \%$ & $14.4 \%$ & $70.8 \%$ \\
\hline & & $<50 \%$ & 0.75 & $72.0 \%$ & $77.1 \%$ & $56.1 \%$ & $80.2 \%$ & $14.2 \%$ & $76.3 \%$ \\
\hline & & Sen & vity $A$ & alyses $^{\dagger}$ & & & & & \\
\hline Sconario & O/ Claccified & FE & $\mathbf{A U C}$ & Thres & hold >0 & Threst & hold $\geq 0.5$ & Thre & hold 1 \\
\hline Scenario & $\%$ Classmimed & $\mathbf{E F}$ & AUC & Sn & PPV & Sn & PPV & Sn & PPV \\
\hline E\&M \& Principal & $56+5+2$ & $\leq 40 \%$ & 0.75 & $91.9 \%$ & $66.2 \%$ & $91.3 \%$ & $67.0 \%$ & $87.6 \%$ & $68.3 \%$ \\
\hline$(n=115,001)$ & (5J.0 & $<50 \%$ & 0.80 & $89.4 \%$ & $82.0 \%$ & $88.6 \%$ & $82.7 \%$ & $84.5 \%$ & $83.9 \%$ \\
\hline Principal Inpatient & $0607-4+29$ & $\leq 40 \%$ & 0.77 & $91.4 \%$ & $71.8 \%$ & --- & --- & --- & --- \\
\hline$(\mathrm{n}=71,932)$ & & $<50 \%$ & 0.82 & $88.6 \%$ & $86.2 \%$ & --- & --- & --- & --- \\
\hline EF Within 30 Days of & $805 \%$ & $\leq 40 \%$ & 0.77 & $92.1 \%$ & $61.2 \%$ & $91.0 \%$ & $63.1 \%$ & $83.4 \%$ & $65.6 \%$ \\
\hline$(n=223,816)$ & $00.5 \%$ & $<50 \%$ & 0.82 & $89.8 \%$ & $78.9 \%$ & $88.3 \%$ & $80.9 \%$ & $80.1 \%$ & $83.2 \%$ \\
\hline$\geq 4$ Diagnoses in Prior & $046 \%$ & $\leq 40 \%$ & 0.79 & $94.9 \%$ & $61.8 \%$ & $92.5 \%$ & $66.3 \%$ & $77.7 \%$ & $72.1 \%$ \\
\hline Year $(n=75,253)$ & 94.010 & $<50 \%$ & 0.85 & $93.2 \%$ & $78.3 \%$ & $89.7 \%$ & $82.9 \%$ & $73.3 \%$ & $87.8 \%$ \\
\hline Diagnoses from Prior & $736+2 \div 3$ & $\leq 40 \%$ & 0.76 & $90.3 \%$ & $60.7 \%$ & $90.0 \%$ & $61.4 \%$ & $86.2 \%$ & $62.7 \%$ \\
\hline 90 Days $(n=274,202)$ & $10.0 \%$ & $<50 \%$ & 0.80 & $87.5 \%$ & $78.4 \%$ & $87.0 \%$ & b $79.1 \%$ & $82.9 \%$ & $80.3 \%$ \\
\hline
\end{tabular}


medRxiv preprint doi: https://doi.org/10.1101/2021.09.15.21263651; this version posted September 17, 2021. The copyright holder for this preprint (which was not certified by peer review) is the author/funder, who has granted medRxiv a license to display the preprint in perpetuity. All rights reserved. No reuse allowed without permission.

* Codes not listed (I50.814, Right Heart Failure due to Left HF; I50.83, High Output HF; I09.81, Rheumatic HF) were classified as non-specific due to total count $<1,000$ in the database; $†$ Sensitivities for predictor (1): proportion of specific HF codes classified as HFrEF-related;

Abbreviations: AUC indicates area under the curve; EF, ejection fraction; E\&M, evaluation and management; pEF, preserved ejection fraction; $\mathrm{PPV}$, positive predictive value; $\mathrm{rEF}$, reduced ejection fraction; Sn, sensitivity. 
medRxiv preprint doi: https://doi.org/10.1101/2021.09.15.21263651; this version posted September 17, 2021. The copyright holder for this preprint (which was not certified by peer review) is the author/funder, who has granted medRxiv a license to display the preprint in perpetuity. All rights reserved. No reuse allowed without permission.

\section{REFERENCES}

1. Desai RJ, Lin KJ, Patorno E, et al. Development and Preliminary Validation of a Medicare Claims-Based Model to Predict Left Ventricular Ejection Fraction Class in Patients With Heart Failure. Circ Cardiovasc Qual Outcomes. 2018;11(12):e004700.

2. Heidenreich PA, Natarajan S, Bahrami H. Accuracy of Administrative Coding to Identify Reduced and Preserved Left Ventricular Ejection Fraction. J Card Fail. 2019;25(6):486489.

3. Masri A, Althouse AD, McKibben J, Lee JS, Mulukutla SR. Limitations of Administrative Data for Studying Patients Hospitalized With Heart Failure. Ann Intern Med. 2017;166(12):916-917.

4. Patterson OV, Freiberg MS, Skanderson M, S JF, Brandt CA, DuVall SL. Unlocking echocardiogram measurements for heart disease research through natural language processing. BMC Cardiovasc Disord. 2017;17(1):151.

5. Mahesri M, Chin K, Kumar A, et al. External validation of a claims-based model to predict left ventricular ejection fraction class in patients with heart failure. PLoS One. 2021;16(6):e0252903. 